\title{
Eosinophilic esophagitis: an emerging disease in childhood - review of diagnostic and management strategies
}

\author{
Alexandra Papadopoulou ${ }^{1}$ and Jorge Amil Dias ${ }^{2}$ * \\ 1 First Department of Pediatrics, Athens Children's Hospital "Agia Sofia," University of Athens, Athens, Greece \\ ${ }^{2}$ Department of Pediatrics, Hospital S. João, Porto, Portugal
}

\section{Edited by:}

(Keith) Chee Yee Ooi, University of New South Wales, Australia

\section{Reviewed by:}

Helen M. Evans, Starship Children's

Hospital, New Zealand

Scott Nightingale, John Hunter

Children's Hospital, Australia

\section{*Correspondence:}

Jorge Amil Dias, Pediatric

Gastroenterology Unit, Department of

Pediatrics, Hospital S. João, Alameda

Hernani Monteiro, Porto 4202-451,

Portugal

e-mail:jamildias@zonmail.pt
Eosinophilic esophagitis is a chronic immune/antigen mediated inflammatory disease of the esophagus. It comprises a separate entity of increasing incidence and prevalence in children and adults. The disease is characterized by histological evidence of dense esophageal tissue eosinophilia in the presence of a variety of upper Gl symptoms including vomiting, dysphagia, food impaction, and odynophagia. Cornerstone of treatment is dietary intervention and/or the off-label use of swallowed topical corticosteroids. New drug therapies are under investigation. In this review, we focus on the diagnostic approach and the currently available treatment strategies.

Keywords: eosinophilic esophagitis, oral viscous budesonide, fluticasone propionate, oral steroids, amino acidbased formula, empiric elimination diet, targeted elimination diet

\section{INTRODUCTION}

Eosinophilic esophagitis (EoE) is a chronic immune/antigen mediated esophageal inflammatory disease associated with esophageal dysfunction, resulting from severe eosinophil-predominant inflammation (1). The prevalence of the disease varies from 0.89/10,000 in Western Australia (2) to 4/10,000 children in Ohio (3) while, in Europe, the incidence of the disease was reported to be $0.16 / 10,000$ in Southern Denmark (4). A recent paper reveals that incidence and prevalence has increased considerably throughout the world (5). Exact epidemiologic figures depend on availability of endoscopy services, medical awareness, and diagnostic protocol.

Eosinophilic esophagitis is a disease with several phenotypes [e.g., structuring/gastro esophageal reflux disease (GERD)like/dysmotility], which need to be better defined in order to clarify long-term complications such as the development of fibrosis. The disease is more common in males and in patients with atopic diseases (6). Studies conducted in children suggest that in many patients, symptoms of EoE are triggered by food allergens (1). Experimental models suggest that other sources of antigen exposure beyond food may also cause EoE (7) and a recent report describes three adults developing EoE after clearly identified exposure to aeroallergens (8). Whether this occurs also in pediatric patients remains to be demonstrated, although seasonal exacerbation of the disease has been reported in children with EoE (9). The elimination of specific foods from the patient's diet is associated with disease remission while, their reintroduction induces relapse. However, the methodology for identification of potentially significant food- or aero-antigens requires further development as the currently available allergy tests often give false positive or false negative results leading to the incomplete elimination of causative food allergens from the patient's diet and to inability to resolve symptoms and histological abnormalities. The first consensus recommendations for diagnosis and treatment of EoE were published in 2007 by a group of experts who updated them in 2011 (1) while, more recent guidelines were published by American College of Gastroenterology (10), and the ESPGHAN (11). The latter, provided practical management guidelines of childhood EoE based on evidence where available and on expert opinion where evidence was lacking, and also, practical diagnostic and management algorithms to guide pediatric gastroenterologists in clinical practice. In the present review, we discuss diagnosis and treatment options of childhood EoE.

\section{CLINICAL MANIFESTATIONS OF EOE AND DIAGNOSTIC APPROACH}

The clinical manifestations of EoE are variable depending on age and the disease phenotypes. Feeding difficulties are the most common symptoms in infants and toddlers, vomiting and pain in children, and dysphagia and food impaction in adolescents. Patients with EoE may or may not be atopic. Total IgE and specific IgE to food antigens (RAST tests) are not reliable for the identification of causative foods of EoE. Skin prick tests (SPT) and allergen patch tests (APT) can be used but the latter need validation and are not available everywhere. The foods that are considered for testing with skin SPT and APT tests include milk protein, egg, peanuts, soy, a variety of grains (wheat, rice, corn, rye, oats, and barley), meats (beef, pork, chicken, and turkey), fish, and shellfish. The positive predictive values of SPTs in children with EoE were reported to range between 26 and $86 \%$ (highest for milk) while the negative predictive values ranged between 29 and $99 \%$ (highest for peanut) (6). The sensitivity and specificity of the tests varied between $18-88$ and $82-97 \%$, respectively (6). Therefore, isolated 
SPTs may have a better value to exclude rather to confirm relation to specific foods. The combination of SPTs and APT tests increased the negative predictive value to an average of $92 \%$ with the exception of milk (at $44 \%$ ), while the positive predictive value remained low (at 44\%) (6). As the most common food triggers of EoE the following have been recognized: milk (55\%), wheat $(33 \%)$, nuts (33\%), and seafood (11\%) in adults (12) with EoE while, in children (6), milk was the most common food identified, followed by wheat, soy, and eggs (6). The use of allergy tests is limited by common false positive and false negative results. The identification of food allergens in patients with EoE may mean concomitant food allergy without those foods being the precipitating cause of the disease. On the other hand, elimination diets may still contain the offending product in occult form leading to refractoriness to the elimination diet.

Unfortunately, there are no available specific biomarkers for the diagnosis of the disease, the monitoring of the response to treatment, and the disease prognosis. Therefore, the disease diagnosis relies currently only on endoscopy and histology (3). The endoscopic features of the disease vary from normal esophagus to the presence of esophageal rings, furrows, and/or white exudates (Figures 1A-C) indicative of eosinophilic microabscesses and less often narrowing of the caliber of esophagus (13). The presence of mucosal breaks (erosions or ulceration) are not indicative of EoE but of GERD, Crohn's disease, or other diagnoses. The main histologic feature of EoE is striking eosinophilia of esophageal mucosa, usually along with microabscesses, superficial layering, or extracellular eosinophil granules (Figure 2). The presence of at least 15 eosinophils per high-power field found in at least 1 esophageal mucosal biopsy (peak value) is required for the histological definition of the disease. At least three esophageal biopsies are needed from different parts of esophagus to achieve a diagnosis of EoE in $97 \%$ of patients (14) and five, to achieve a diagnosis of EoE in 100\% (15). The need for multiple biopsies derives from the fact that eosinophils are recruited from the deeper layers of the esophageal wall and areas with lower eosinophil density may exist in endoscopic superficial mucosal biopsies (16). If we rely, therefore, on a limited number of superficial mucosal biopsies, the diagnosis of EoE may be missed. Furthermore, it should be noted that esophageal eosinophilia is not an exclusive feature of EoE. Other diseases that are associated with esophageal eosinophilia are GERD, Crohn's disease, connective tissue disease, infectious esophagitis (herpes, Candida), celiac disease, achalasia, graft-versus-host disease, drug hypersensitivity, eosinophilic gastroenteritis, and hyper eosinophilic syndrome $(1,17)$. Gastric and duodenal biopsies should also be taken on first diagnostic endoscopy to identify or exclude other conditions like eosinophilic gastroenteropathy. The discussion of this poorly characterized disease is beyond the scope of this paper. GERD is the main differential diagnosis from EoE. GERD can present with similar symptoms as EoE or even co-exist with EoE. There are studies proposing scoring systems to differentiate between GERD and EoE, based on clinical and endoscopic features: male gender, dysphagia, history of food impaction, absence of pain/heartburn, linear furrowing, and white papules (18). Such systems may be useful in older children and in adolescents (18). The identification of mucosal inflammatory mediators related to eosinophil activation
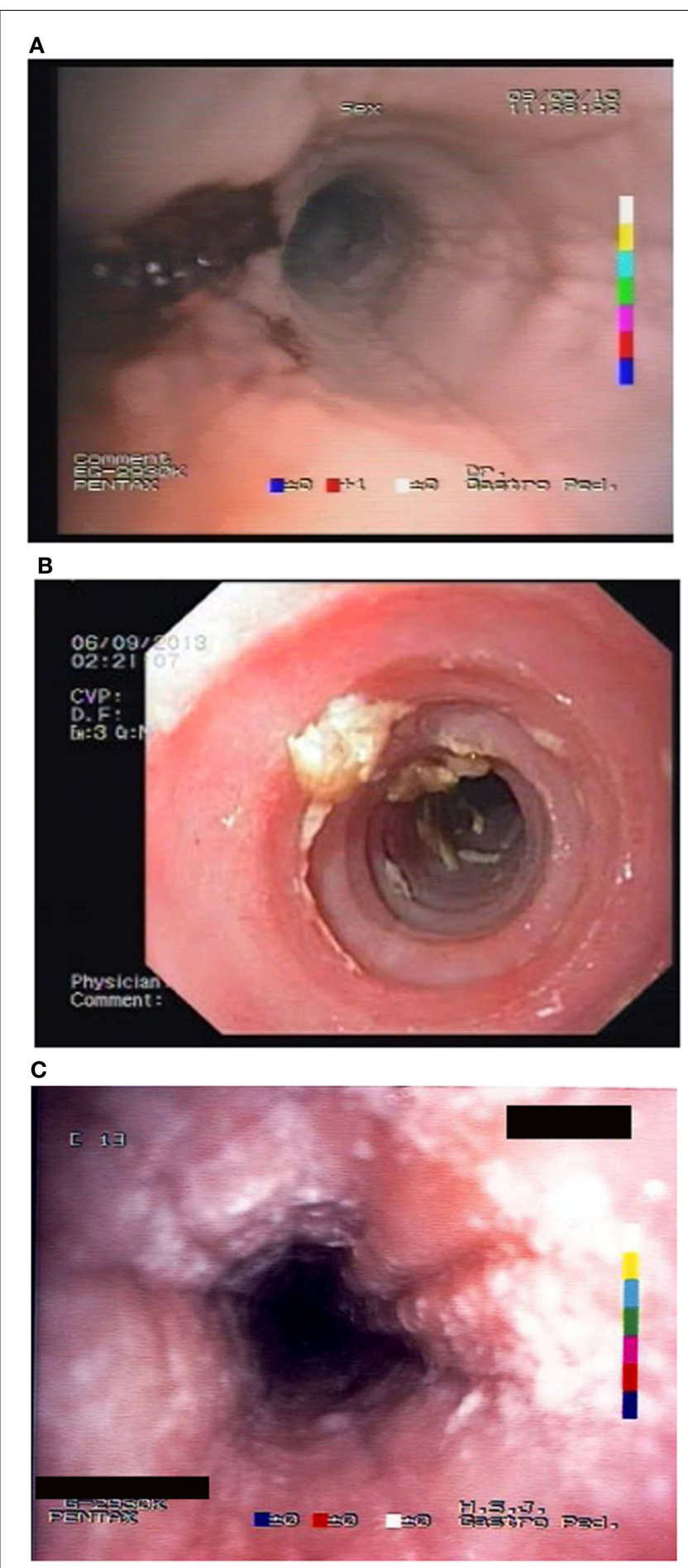

FIGURE 1 | Endoscopic appearance of EoE showing (A) friability of the mucosa and easy bleeding; $(B)$ trachealisation of esophagus with remains of recent food impaction; and (C) edema with furrows and white spots of eosinophil granulomas.

has also been tested and may give new diagnostic options and accuracy (19). Until more data become available, however, there is a wide consensus that patients need endoscopic and histologic 


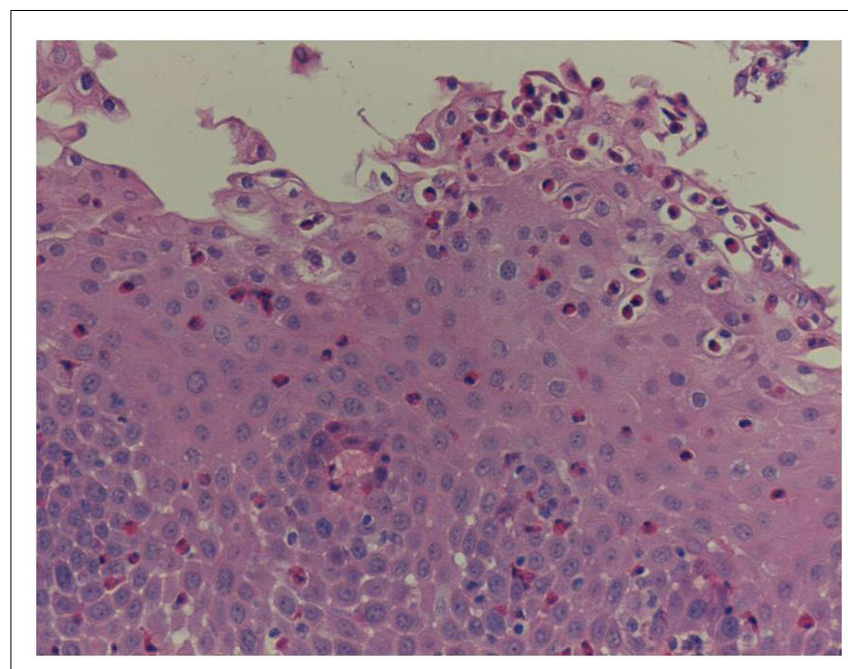

FIGURE 2 | Histology of EoE with marked infiltration of eosinophils in the mucosa

assessment after a course of 2 months trial with antisecretory drugs (proton-pump inhibitors, PPIs). Those patients with esophageal eosinophilia who improve both clinically and histologically after the treatment with PPIs are currently classified as having either GERD or PPI-responsive esophageal eosinophilia (PPI-REE). Further studies are required to show whether PPI-REE is a separate entity or it comprises a subtype of EoE or GERD. The ability of PPIs to achieve resolution of esophageal eosinophilia is attributed to acid-suppression but also to possible inhibition of various other inflammatory mechanisms $(1,20,21)$. The lack of response to high-dose proton-pump inhibitors is necessary to fulfill the current definition criteria for the disease $(1,11)$. The recommended dose of PPIs is $1 \mathrm{mg} / \mathrm{kg}$ per dose, twice daily with maximum dose reaching adult dose $20-40 \mathrm{mg}$ once or twice daily depending on patient and PPI. After the confirmation of the diagnosis of EoE, PPIs are usually stopped unless there is evidence of coexisting GERD. In that case, PPIs may be continued as adjunctive therapy to other specific for EoE interventions (1). A practical algorithm on the diagnostic approach of children and adolescents with symptoms suggesting EoE is given in the position paper recently published by ESPGHAN (11).

\section{MANAGEMENT OF EoE}

The goals of treatment of EoE are to achieve and maintain clinical and histological remission of the disease and to prevent iatrogenic damage such as nutritional compromise due to long-term elimination diet. Until minimal invasive tests measuring biochemical products of eosinophil activation are available to facilitate adequate monitoring of the inflammatory process, the confirmation of histological remission of the disease with repeat endoscopy and biopsies before food reintroduction or drug titration, is necessary.

Dietary elimination and/or the off-label use of topical corticosteroids is usually associated with reversal of symptoms and histological abnormalities of the esophagus. A practical algorithm to treatment approach is given in the position paper recently published by ESPGHAN (11). It should be noted, however, that the optimal intervention needs to be individualized as atopic patients most likely benefit from the elimination diet and the non-atopic from steroids. Unfortunately, it is not always easy to identify the causative foods while, not all of the atopic patients are sensitized to the same foods and others are sensitized to aero allergens.

\section{DIETARY TREATMENT}

Three elimination diets have been developed for patients with EoE: (1) amino acid-based formula (AAF); (2) targeted elimination diet (TED); and (3) empiric elimination diet (EED).

Case series suggest all of the above diets are effective in inducing clinical and histological remission in patients with EoE $(6,22-28)$ with AAF being the most successful (Table 1), It should be noted, however, that, to date, there are no randomized controlled trials investigating the efficacy of any of these diets. There also has not been any head-to-head comparison of these different modes of treatment and different centers have developed varying levels of expertise in administration of them, which is likely to influence management preference.

The AAF consists of complete removal of food allergens from the diet substituted by a hypoallergenic formula based on amino acids (23). Several studies reported efficacy of AAF in achieving clinical and histological remission of EoE in both children $(22,24)$ and in adults $(28)$. Resolution of clinical symptoms such as vomiting, abdominal pain, or dysphagia in children $(22,24)$ and dysphagia, chest pain, food impaction, or heartburn in adults (28), was reported as early as at 8 days $(22)$ or at 2 weeks $(24,28)$ of introduction while, histological resolution was reported at 4 weeks (22, $24,28)$. Despite these encouraging reports of remission induction, long-term use of the AAF is severely curtailed by its many disadvantages including the high cost of AAF and the frequent need for nasogastric tube placement or even gastrostomy due to poor long-term palatability. Currently, AAF is reserved for young infants with multiple food allergies as well as for patients who do not respond or do not wish to follow strict diet with multiple food elimination.

Owing to the poor long-term acceptability of AAF, the TED, which removes foods based on a combination of suggestive history of food triggers and results of SPTs and (in some centers) APT was evaluated. The benefit of TED to induce remission in children has been variable from non- to moderate (29) or high (6) among those with positive SPTs and/or APT. It should be noted, however, that some patients with EoE have intolerance to multiple food antigens some of which may have not been identified by skin tests. Furthermore, the identified food antigens with SPTs and/or APT may not necessarily be the causative foods of the disease. Therefore, relying only on tests, which have often false positive or false negative results may lead to elimination from the diet of only part of the offending food antigens, and failure to induce remission.

Another dietary strategy for treating EoE is with the use of EED, which removes from the diet independently of sensitization, the known allergens that strongly correlate with EoE, which are often the dairy products, soy, eggs, wheat, peanuts, fish, and shellfish (27). This diet strategy has been used in treating children with EoE achieving clinical and histological improvement in $74 \%$ of patients (27), although a more recent study reported a lower percentage of the patients showing histological remission $(53 \%$ of 
Table 1 | Outcomes of studies on dietary treatment of eosinophilic esophagitis.

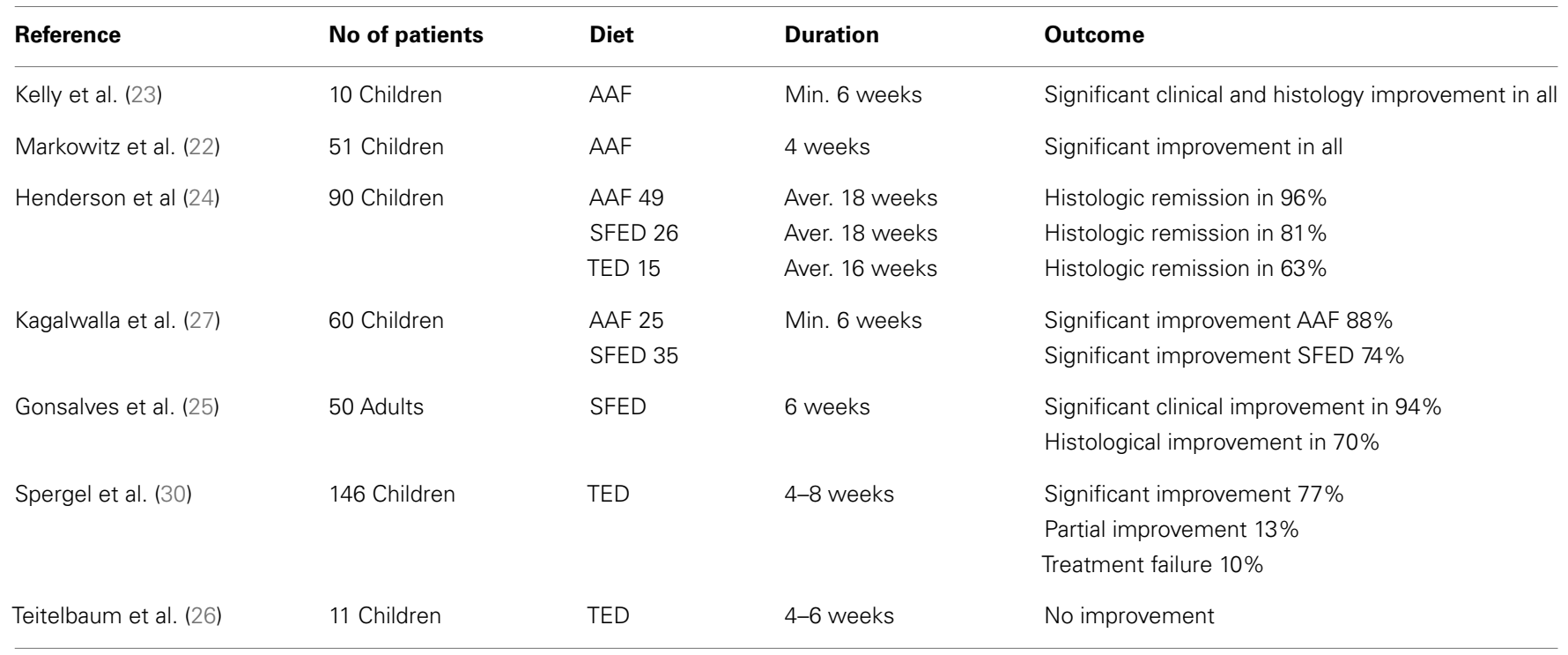

patients), which was attributed by the authors to the poor dietary compliance (6).

The performance of diet treatment requires supervision by an experienced dietitian to ensure compliance with the diet and that proper amount of calories, vitamins, and micronutrients are maintained (11). Nutritional status of the patient needs to be evaluated longitudinally in order to identify early nutritional impairment and apply appropriate measures to reverse it (11).

\section{HOW TO ASSESS THE EFFICACY OF THE DIET?}

Histological response does not correlate with clinical response. Relying on symptom reversal for the assessment of the efficacy of a therapeutic intervention may be misleading, allowing perpetuation of esophageal inflammation. The recommendation, therefore, is to assess the efficacy of the chosen treatment with a repeat endoscopy following resolution of symptoms after commencing dietary elimination (11). In case AAF is chosen, the repeat endoscopy may be performed at 4 weeks as the resolution of symptoms is achieved earlier. In case of TED or EED, the resolution of symptoms is expected later and therefore the repeat endoscopy is suggested at 8-12 weeks from the introduction. In case of histological remission, food reintroduction is considered starting from the least allergenic foods (30). During food reintroduction, those foods that prove to trigger EoE symptoms may need to be indefinitely restricted (1). Some units advise the invasive approach of performing periodic endoscopies to assure maintenance of combined symptomatic and histological remission following food reintroduction and suggest a re-endoscopy after reintroduction of all of the foods of similar allergenicity from vegetables, fruits, grains, and meat. More studies are required to show whether the measurement of specific inflammatory mediators through non-invasive techniques may allow an easier monitoring of the tolerance to specific foods.

As stated above, dietary treatment is particularly effective in treating EoE in atopic children. Patients without a history of atopy are relatively refractory to dietary treatment and require initiation of drug therapy (31). In some patients, there is evidence that seasonal exacerbations caused by inhaled aeroallergens (including pollens and molds) may occur, often characterized by food bolus impaction (32). It is, therefore, important to enquire about seasonal exacerbations and, if present, to try to identify triggering aeroallergens. In case of an established pattern of seasonal exacerbations, preventive measures with dietary restrictions and/or the use of topical corticosteroids may be suggested.

\section{DRUG THERAPY}

Among the medications that have been assessed in pediatric patients with EoE with different success, are corticosteroids (oral systemic and topical), cromolyn sodium, leukotriene receptor antagonists, and biologics (mainly anti-IgE and anti-IL-5 monoclonal antibodies). From those, only oral systemic and topical corticosteroids proved to be highly effective in treating children with EoE (Table 2). It should be noted, however, that there are only few randomized controlled trials assessing the efficacy of different drug agents, therefore, further studies are needed to have a universal approach to EoE treatment.

\section{TOPICAL AND SYSTEMIC ORAL STEROIDS}

Oral systemic and topical steroids are both highly effective in inducing clinical and histological remission in adults and in children with EoE with minor side effects such as oral candidiasis, resolving following drug discontinuation. The clinical remission following oral steroids is achieved as early as at 1 week from the start of treatment and the resolution of histologic lesions at 4 weeks (33). Unfortunately, the discontinuation of drug therapy is often associated with relapse of the disease and the need for a repeated course of treatment. Considering, therefore, the risks associated with the chronic use of oral systemic steroids in children, topical steroids were assessed in patients with EoE and proved effective in achieving resolution of histologic lesions. Studies showed that although oral prednisone achieved a greater degree of histologic regression, there was no statistical difference 
Table 2 | Outcomes of studies on steroid therapy of eosinophilic esophagitis.

\begin{tabular}{|c|c|c|c|c|}
\hline Reference & No of patients & Treatment & Duration & Outcome \\
\hline Liacouras et al. (33) & 20 Children & Oral steroids & 4 weeks & Clinical and histological response in all \\
\hline Teitelbaum et al. (26) & 11 Children & Topical FP open label & 8 weeks & Clinical and histological response in all \\
\hline Remedios et al. (35) & 19 Adults & Topical FP open label & 4 weeks & Clinical and histological response in all \\
\hline Konikoff et al. (36) & 36 Children & $\begin{array}{l}\text { Topical FP randomised } \\
\text { controlled trial }\end{array}$ & 12 weeks & $\begin{array}{l}\text { Clinical improvement } \\
\text { FP: in } 67 \% \\
\text { Placebo: in } 27 \% \\
\text { Histological remission } \\
\text { FP: in } 50 \% \\
\text { Placebo: in } 9 \%\end{array}$ \\
\hline Dohil et al. (38) & 24 Children & Topical OVB DBCT & 12 weeks & $\begin{array}{l}\text { Clinical improvement } \\
\text { OVB: in } 87 \% \\
\text { Placebo: in none } \\
\text { Histological improvement OVB: in } 87 \% \\
\text { Placebo: in } 0 \%\end{array}$ \\
\hline Straumann et al. (39) & $\begin{array}{l}36 \text { Adolescents } \\
\text { and adults }\end{array}$ & Topical OVB DBCT & 2 weeks & $\begin{array}{l}\text { Clinical improvement } \\
\text { OVB: in } 72 \% \\
\text { Placebo: in } 22 \% \text { histological } \\
\text { improvement following OVB but not } \\
\text { following placebo }\end{array}$ \\
\hline
\end{tabular}

with regards to symptom resolution, symptom relapse, or time of relapse (34). The use of systemic corticosteroids, therefore, is only considered when immediate relief of the patient's symptoms such as severe dysphagia, dehydration, weight loss, or esophageal strictures, is needed. In all other case, the topical steroids are considered as first line drug treatment for EoE. The effective dose for eliminating clinical symptoms and histologic abnormalities is $1-2 \mathrm{mg} / \mathrm{kg} /$ day of prednisone with maximum dose reaching $40-60 \mathrm{mg}$.

The topical steroids, which have been used in treating EoE, are swallowed fluticasone propionate and oral viscous budesonide (OVB). Fluticasone propionate is sprayed into the mouth with lips sealed around the device and the patient is advised to not drink or eat for the next $30 \mathrm{~min}$ (35). This drug was effective in both adults (35) and children (26) with EoE and was reported to induce remission in 50 (36) to $91 \%$ of the patients (37). The suggested dosage ranges from 88 to $440 \mu \mathrm{g}$ twice to four times daily for children and 440-880 $\mu \mathrm{g}$ twice daily for adolescents/ adults (1).

Oral viscous budesonide is also an option for treating EoE. It is prepared by mixing liquid solution of budesonide $1 \mathrm{mg} / 2 \mathrm{ml}$ (the preparation used for inhalations) and $5 \mathrm{~g}$ of sucralose. The administration of this preparation achieves regression of symptoms and of endoscopic and histologic abnormalities in $87 \%$ of children (38) and in $72 \%$ of adolescents and adults with EoE (39). The recommended dosage of OVB is $1 \mathrm{mg}$ daily for children $<10$ years and $2 \mathrm{mg}$ daily for older children and adults (1). Both topical preparations may induce remission of inflammation as documented in various studies but the OVB may provide increased concentration of the drug in the esophagus (40).
Drug titration should be initiated after confirming histologic remission following symptoms resolution with a repeat endoscopy, at 4-12 weeks following drug introduction (11).

It should be noted, however, that similarly to oral systemic corticosteroids, the discontinuation of topical steroids is associated with relapse of symptoms as early as at 4 months (38) or according to others at a mean time of 8.8 months (37) requiring maintenance therapy. In adults with EoE, a low-dose (twice daily $0.25 \mathrm{mg}$ ) of OVB maintained quiescent EoE in remission (41). In children, although the need for maintenance treatment is often recognized, the optimal regimen still needs to be determined.

\section{OTHER DRUG THERAPIES}

Other drug therapies such as sodium cromoglycate or montelukast, a leukotriene receptor antagonist, are not recommended for treating EoE unless more favorable data become available $(1,11)$. The same is true for immunomodulating drugs and biologics (42). The efficacy of antibodies against IL-5 in patients with EoE is controversial showing variable results and relapse upon discontinuation, while anti-IgE monoclonal antibodies were effective in improving food tolerance and reversing symptoms but not in improving endoscopic and histological abnormalities (43).

\section{FOLLOW-UP OF ASYMPTOMATIC PATIENTS}

The follow-up of asymptomatic patients is not universal and differs widely among centers with some performing periodic endoscopic re-evaluations while, others not. Considering that long-term complications of the asymptomatic disease are poorly 
defined, the follow-up of asymptomatic patients should be individualized considering disease phenotype and severity (11).

As mentioned above, there may be a discrepancy between symptoms and histological features. Medical advice may be therefore guided to promote inflammation-free esophageal mucosa with follow-up endoscopies, but this ambitious goal has to be adjusted to individual patients.

\section{ESOPHAGEAL DILATATION}

Esophageal dilatation (ED) has been used mainly in adults with EoE (44). ED can be helpful in acutely symptomatic patients who present with severe dysphagia due to marked esophageal narrowing after failure of medical treatment to improve symptoms (45). It should be stressed, however, that before deciding on $\mathrm{ED}$, it is mandatory to try medical and/or dietary therapy (11).

\section{CONCLUSION}

Eosinophilic esophagitis is a chronic, relapsing inflammatory disease of the esophagus, which requires often repeated or prolonged therapy. The definition of the disease phenotypes, and the development of biomarkers, to evaluate the response to treatment and the early relapse, will allow guide more precisely short- and long-term management of the disease.

\section{REFERENCES}

1. Liacouras CA, Furuta GT, Hirano I, Atkins D, Attwood SE, Bonis PA, et al. Eosinophilic esophagitis:updated consensus recommendations for children and adults. J Allergy Clin Immunol (2011) 128:3-20. doi:10.1016/j.jaci.2011.02.040

2. Cherian S, Smith NM, Forbes DA. Rapidly increasing prevalence of eosinophilic oesophagitis in Western Australia. Arch Dis Child (2006) 91(12):1000-4. doi:10. 1136/adc.2006.100974

3. Noel RJ, Putnam PE, Rothenberg ME. Eosinophilic esophagitis. N Engl J Med (2004) 351(9):940-1. doi:10.1056/NEJM200408263510924

4. Dalby K, Nielsen RG, Kruse-Andersen S, Fenger C, Bindslev-Jensen C, Ljungberg $\mathrm{S}$, et al. Eosinophilic oesophagitis in infants and children in the region of southern Denmark: a prospective study of prevalence and clinical presentation. J Pediatr Gastroenterol Nutr (2010) 51(3):280-2. doi:10.1097/MPG. 0b013e3181d1b107

5. Soon IS, Butzner JD, Kaplan GG, deBruyn JC. Incidence and prevalence of eosinophilic esophagitis in children. J Pediatr Gastroenterol Nutr (2013) 57(1):72-80. doi:10.1097/MPG.0b013e318291fee2

6. Spergel JM, Brown-Whitehorn TF, Cianferoni A, Shuker M, Wang ML, Verma R, et al. Identification of causative foods in children with eosinophilic esophagitis treated with an elimination diet. J Allergy Clin Immunol (2012) 130(2):461-7. doi:10.1016/j.jaci.2012.05.021

7. Mishra A, Hogan SP, Brandt EB, Rothenberg ME. An etiological role for aeroallergens and eosinophils in experimental esophagitis. J Clin Invest (2001) 107(1):83-90. doi:10.1172/JCI10224

8. Wolf WA, Jerath MR, Dellon ES. De-novo onset of eosinophilic esophagitis after large volume allergen exposures. J Gastrointestin Liver Dis (2013) 22(2):205-8.

9. Wang FY, Gupta SK, Fitzgerald JF. Is there a seasonal variation in the incidence or intensity of allergic eosinophilic esophagitis in newly diagnosed children? J Clin Gastroenterol (2007) 41(5):451-3. doi:10.1097/01.mcg.0000248019.16139.67

10. Dellon ES, Gonsalves N, Hirano I, Furuta GT, Liacouras CA, Katzka DA, et al. ACG clinical guideline: evidenced based approach to the diagnosis and management of esophageal eosinophilia and eosinophilic esophagitis (EoE). Am J Gastroenterol (2013) 108(5):679-92. doi:10.1038/ajg.2013.71

11. Papadopoulou A, Koletzko S, Heuschkel R, Dias JA, Allen KJ, Murch SH, et al. Management guidelines of eosinophilic esophagitis in childhood. J Pediatr Gastroenterol Nutr (2014) 58(1):107-18. doi:10.1097/MPG.0b013e3182a80bel

12. Gonsalves N, Doerfler B, Hirano I. Long term maintenance therapy with dietary restriction in adults with eosinophilic esophagitis. Gastroenterology (2011) 140(5):S180-1. doi:10.1016/S0016-5085(11)60729-4
13. Furuta G. Eosinophilic esophagitis. Dig Dis (2009) 27(Suppl 1):122-8. doi:10. $1159 / 000268132$

14. Shah A, Kagalwalla AF, Gonsalves N, Melin-Aldana H, Li BU, Hirano I. Histopathologic variability in children with eosinophilic esophagitis. Am J Gastroenterol (2009) 104(3):716-21. doi:10.1038/ajg.2008.117

15. Gonsalves N, Policarpio-Nicolas M, Zhang Q, Rao MS, Hirano I. Histopathologic variability and endoscopic correlates in adults with eosinophilic esophagitis. Gastrointest Endosc (2006) 64(3):313-9. doi:10.1016/j.gie.2006.04.037

16. Saffari H, Peterson KA, Fang JC, Teman C, Gleich GJ, Pease LF III. Patchy eosinophil distributions in an esophagectomy specimen from a patient with eosinophilic esophagitis: implications for endoscopic biopsy. J Allergy Clin Immunol (2012) 130(3):798-800. doi:10.1016/j.jaci.2012.03.009

17. Dahms BB. Reflux esophagitis: sequelae and differential diagnosis in infants and children including eosinophilic esophagitis. Pediatr Dev Pathol (2004) 7(1):5-16. doi:10.1007/s10024-003-0203-5

18. Mulder DJ, Hurlbut DJ, Noble AJ, Justinich CJ. Clinical features distinguish eosinophilic and reflux-induced esophagitis. J Pediatr Gastroenterol Nutr (2013) 56(3):263-70. doi:10.1097/MPG.0b013e3182794466

19. Furuta GT, Kagalwalla AF, Lee JJ, Alumkal P, Maybruck BT, Fillon S, et al. The oesophageal string test: a novel, minimally invasive method measures mucosal inflammation in eosinophilic oesophagitis. Gut (2013) 62(10):1395-405. doi: 10.1136/gutjnl-2012-303171

20. Handa O, Yoshida N, Fujita N, Tanaka Y, Ueda M, Takagi T, et al. Molecular mechanisms involved in anti-inflammatory effects of proton pump inhibitors. Inflamm Res (2006) 55(11):476-80. doi:10.1007/s00011-006-6056-4

21. Yoshida N, Yoshikawa T, Tanaka Y, Fujita N, Kassai K, Naito Y, et al. A new mechanism for anti-inflammatory actions of proton pump inhibitors - inhibitory effects on neutrophil-endothelial cell interactions. Aliment Pharmacol Ther (2000) 14(Suppl 1):74-81. doi:10.1046/j.1365-2036.2000.014s1074.x

22. Markowitz JE, Spergel JM, Ruchelli E, Liacouras CA. Elemental diet is an effective treatment for eosinophilic esophagitis in children and adolescents. Am J Gastroenterol (2003) 98(4):777-82. doi:10.1111/j.1572-0241.2003.07390.x

23. Kelly KJ, Lazenby AJ, Rowe PC, Yardley JH, Perman JA, Sampson HA. Eosinophilic esophagitis attributed to gastroesophageal reflux: improvement with an amino acid-based formula. Gastroenterology (1995) 109(5):1503-12. doi:10.1016/0016-5085(95)90637-1

24. Henderson CJ, Abonia JP, King EC, Putnam PE, Collins MH, Franciosi JP, et al. Comparative dietary therapy effectiveness in remission of pediatric eosinophilic esophagitis. J Allergy Clin Immunol (2012) 129(6):1570-8. doi:10.1016/j.jaci. 2012.03.023

25. Gonsalves N, Yang GY, Doerfler B, Ritz S, Ditto AM, Hirano I. Elimination diet effectively treats eosinophilic esophagitis in adults; food reintroduction identifies causative factors. Gastroenterology (2012) 42(7):1451-9. doi:10.1053/ j.gastro.2012.03.001

26. Teitelbaum JE, Fox VL, Twarog FJ, Nurko S, Antonioli D, Gleich G, et al. Eosinophilic esophagitis in children: immunopathological analysis and response to fluticasone propionate. Gastroenterology (2002) 122(5):1216-25. doi:10. 1053/gast.2002.32998

27. Kagalwalla AF, Sentongo TA, Ritz S, Hess T, Nelson SP, Emerick KM, et al. Effect of six-food elimination diet on clinical and histologic outcomes in eosinophilic esophagitis. Clin Gastroenterol Hepatol (2006) 4(9):1097-102. doi:10.1016/j.cgh.2006.05.026

28. Byrne KR, Clayton F, Vinson LA, Gleich GJ, Fang JC, Boynton KK, et al. S1075 interim analysis of the utility of an elemental diet in adult eosinophilic esophagitis. Gastroenterology (2010) 138(5):S173. doi:10.1016/S0016-5085(10)60791-3

29. Lamba R, Feuling MB, Levy MB, Noel RJ. Allergy testing in pediatric eosinophilic esophagitis - identification of IgE and delayed hypersensitivity food reactions and its impact on management. Gastroenterology (2011) 140(5):S243. doi:10.1016/S0016-5085(11)60976-1

30. Spergel JM, Andrews T, Brown-Whitehorn TF, Beausoleil JL, Liacouras CA. Treatment of eosinophilic esophagitis with specific food elimination diet directed by a combination of skin prick and patch tests. Ann Allergy Asthma Immunol (2005) 95(4):336-43. doi:10.1016/S1081-1206(10)61151-9

31. Noel RJ, Putnam PE, Collins MH, Assa'ad AH, Guajardo JR, Jameson SC, et al. Clinical and immunopathologic effects of swallowed fluticasone for eosinophilic esophagitis. Clin Gastroenterol Hepatol (2004) 2(7):568-75. doi:10.1016/S15423565(04)00240-X

32. Moawad FJ, Veerappan GR, Lake JM, Maydonovitch CL, Haymore BR, Kosisky $\mathrm{SE}$, et al. Correlation between eosinophilic oesophagitis and aeroallergens. 
Aliment Pharmacol Ther (2010) 31(4):509-15. doi:10.1111/j.1365-2036.2009. 04199.x

33. Liacouras CA, Wenner WJ, Brown K, Ruchelli E. Primary eosinophilic esophagitis in children: successful treatment with oral corticosteroids. J Pediatr Gastroenterol Nutr (1998) 26(4):380-5. doi:10.1097/00005176-199804000-00004

34. Schaefer ET, Fitzgerald JF, Molleston JP, Croffie JM, Pfefferkorn MD, Corkins $\mathrm{MR}$, et al. Comparison of oral prednisone and topical fluticasone in the treatment of eosinophilic esophagitis: a randomized trial in children. Clin Gastroenterol Hepatol (2008) 6(2):165-73. doi:10.1016/j.cgh.2007.11.008

35. Remedios M, Campbell C, Jones DM, Kerlin P. Eosinophilic esophagitis in adults: clinical, endoscopic, histologic findings, and response to treatment with fluticasone propionate. Gastrointest Endosc (2006) 63(1):3-12. doi:10.1016/j.gie.2005. 07.049

36. Konikoff MR, Noel RJ, Blanchard C, Kirby C, Jameson SC, Buckmeier BK, et al. A randomized, double-blind, placebo-controlled trial of fluticasone propionate for pediatric eosinophilic esophagitis. Gastroenterology (2006) 131(5):1381-91. doi:10.1053/j.gastro.2006.08.033

37. Helou EF, Simonson J, Arora AS. 3-yr-follow-up of topical corticosteroid treatment for eosinophilic esophagitis in adults. Am J Gastroenterol (2008) 103(9):2194-9. doi:10.1111/j.1572-0241.2008.01989.x

38. Dohil R, Newbury R, Fox L, Bastian J, Aceves S. Oral viscous budesonide is effective in children with eosinophilic esophagitis in a randomized, placebocontrolled trial. Gastroenterology (2010) 139(2):418-29. doi:10.1053/j.gastro. 2010.05.001

39. Straumann A, Conus S, Degen L, Felder S, Kummer M, Engel H, et al. Budesonide is effective in adolescent and adult patients with active eosinophilic esophagitis. Gastroenterology (2010) 139(5):1526-37. doi:10.1053/j.gastro.2010.07.048

40. Dellon ES, Sheikh A, Speck O, Woodward K, Whitlow AB, Hores JM, et al. Viscous topical is more effective than nebulized steroid therapy for patients with eosinophilic esophagitis. Gastroenterology (2012) 143(2):321-4. doi:10.1053/j. gastro.2012.04.049

41. Straumann A, Conus S, Degen L, Frei C, Bussmann C, Beglinger C, et al. Long-term budesonide maintenance treatment is partially effective for patients with eosinophilic esophagitis. Clin Gastroenterol Hepatol (2010) 9(5):400-9. doi:10.1016/j.cgh.2011.01.017

42. Straumann A, Bussmann C, Conus S, Beglinger C, Simon HU. Anti-TNF-alpha (infliximab) therapy for severe adult eosinophilic esophagitis. J Allergy Clin Immunol (2008) 122(2):425-7. doi:10.1016/j.jaci.2008.06.012

43. Rocha RVA, Trindade E, Lima R, Tavares M, Lopes J, Dias JA. Omalizumab in the treatment of eosinophilic esophagitis and food allergy. Eur J Pediatr (2011) 170(11):1471-4. doi:10.1007/s00431-011-1540-4

44. Lee GS, Craig PI, Freiman JS, de Carle D, Cook IJ. Intermittent dysphagia for solids associated with a multiringed esophagus: clinical features and response to dilatation. Dysphagia (2007) 22(1):55-62. doi:10.1007/s00455-006-9043-6

45. Robles-Medranda C, Villard F, le Gall C, Lukashok H, Rivet C, Bouvier R, et al. Severe dysphagia in children with eosinophilic esophagitis and esophageal stricture: an indication for balloon dilation? J Pediatr Gastroenterol Nutr (2010) 50(5):516-20. doi:10.1097/MPG.0b013e3181b66dbd

Conflict of Interest Statement: The authors declare that the research was conducted in the absence of any commercial or financial relationships that could be construed as a potential conflict of interest.

Received: 11 August 2014; accepted: 06 November 2014; published online: 21 November 2014.

Citation: Papadopoulou A and Dias JA (2014) Eosinophilic esophagitis: an emerging disease in childhood - review of diagnostic and management strategies. Front. Pediatr. 2:129. doi: $10.3389 /$ fped.2014.00129

This article was submitted to Pediatric Gastroenterology and Hepatology, a section of the journal Frontiers in Pediatrics.

Copyright $(2014$ Papadopoulou and Dias. This is an open-access article distributed under the terms of the Creative Commons Attribution License (CC BY). The use, distribution or reproduction in other forums is permitted, provided the original author(s) or licensor are credited and that the original publication in this journal is cited, in accordance with accepted academic practice. No use, distribution or reproduction is permitted which does not comply with these terms. 


\section{APPENDIX \\ KEY POINTS}

A trial with antisecretory medication is necessary to exclude GERD and PPI-responsive esophageal eosinophilia and to fulfill the diagnostic criteria of EoE.

Elimination diet and/or off-label use of topical corticosteroids are effective measures for treating EoE.

Elimination diet is the first line treatment in atopic children.

Systemic corticosteroids are reserved for patients with severe disease requiring immediate relief, or when other treatments have failed. Cromolyn sodium (sodium cromoglycate) and leukotriene receptor antagonists are not currently recommended for treating EoE due to lack of solid evidence of benefit.

Immunosuppressive drugs and biologics have shown some value but effect has been limited and therefore not yet recommended as standard therapy. 